\title{
Evaluation of Visual Function Test of Central Serous Chorioretinopathy After Intravitreal Bevacizumab
}

\author{
Chunu Shrestha', Sabina Shrestha ${ }^{2}$ and Aparajita Manoranjan ${ }^{3}$
}

${ }^{1}$ RM Kedia Eye Hospital, Birgunj, Nepal

${ }^{2}$ Kathmandu Medical College Teaching Hospital, Sinamangal, Kathmandu, Nepal

${ }^{3}$ Nepal Eye Hospital, Tripureshwor, Kathmandu, Nepal

\begin{abstract}
Introduction: Central Serous Chorioretinopathy (CSCR) is a condition of unknown origin characterised by a serous detachment of the macula, affecting young healthy adults mostly men between the age of 2050 years. It is postulated to occur secondary to a leak from the choriocapillaries through the Retinal Pigment Epithelium (RPE). This study was carried out to evaluate the visual function test of CSCR after intravitreal Bevacizumab.

Methods: This is a hospital based, prospective, interventional, non-comparative study conducted in a tertiary level eye hospital in Nepal from 2016 January to 2017 January. The study included 15 eyes of 15 patients with chronic CSCR, All patients were injected with intravitreal Avastin (IVA) $1.25 \mathrm{mg}(0.05 \mathrm{~mL})$. At baseline and follow up visits, patients had contrast sensitivity, stereopsis, colour vision, BCVA, IOP assessment, FFA, dilated fundus examination, and OCT imaging was used for measurement of central macular thickness.

Results: The mean age of patients was 35 years (26-47 years), $12(80 \%)$ patients were males and three (20\%) were females. 13 out of 15 subjects received one injection while the remaining two cases had two injections. All eyes had gained two or more lines improvement in BCVA at the end of follow up. The mean baseline CRT for all patients was $533 \pm 79.5 \mathrm{~lm}$ (range, 412-677), decreased to $253 \pm 39.2 \mathrm{~lm}$ (range, 192-343) after three months with statistically significant ( $p<0.001$ Wilcoxon sign rank test). Contrast sensitivity by Wilcoxon sign rank test was statistically significant with $\mathrm{p}$ value 0.003 .

Conclusions: Bevacizumab was associated with visual function improvement and reduced neurosensory detachment without adverse events in patients with CSCR.

Keywords: Bevacizumab; Central serous chorioretinopathy; Fundus fluorescein angiography; Optical coherence Tomography
\end{abstract}

Correspondence: Chunu Shrestha, RM Kedia Eye Hospital, Birgunj, Nepal; E-mail: drchunu20@gmail.com.

DOI: $10.3126 / \mathrm{mjsbh.v18i1.21073}$

Submitted on: 2018-09-13

Accepted on: 2018-12-20 


\section{INTRODUCTION}

Central Serous Chorioretinopathy (CSCR) is a condition of unknown origin characterised by a serous detachment of the macula. It afflicts young healthy adults mostly men between the age of 2050 years $^{1}$. It is considered to occur secondary to a leak from the choriocapillaries through the Retinal Pigment Epithelium (RPE). ${ }^{2} \mathrm{~A}$ recent study of choroidal perfusion suggests that choroidal ischemia might play a role in its pathogenesis.

Some patients also would develop into chronic CSCR with poor prognosis which is characterised by the widespread of distribution of small pigment epithelial detachments associated with areas of RPE atrophy and extensive pigmentary changes. $3,4,5$ In rare cases, recurrent detachments and RPE changes can lead to permanent loss of vision. ${ }^{4,6}$

Bevacizumab (Avastin) is now approved by Food and Drug Administration (FDA) as an adjunct for the treatment of metastatic colorectal cancer and metastatic breast cancer in USA. ${ }^{7}$ It is a monoclonal antibody that binds all iso-forms of Vascular Endothelial Growth Factor A (VEGF-A).

The use of Avastin to treat the patients with CSCR was accepted gradually recently. $8,9,10$ However, the potential and uncertain risks and complication of intravitreal injection (IVI) were noted. ${ }^{10,11,12}$

\section{METHODS}

This prospective, interventional, hospital based, non-comparative study conducted in a tertiary level Eye Hospital in Kathmandu, Nepal from January 2016 to January 2017 including 15 eyes of 15 patients with chronic CSCR. Inclusion criteria included documented subfoveal fluid by OCT, active leak associated with the subfoveal fluid, the ability and willingness to provide written informed consent and no signs of choroidal neovascularisation. Patients were excluded if other conditions which could compromise visual acuity were present and if there was a history of photodynamic therapy or intravitreal injection of anti-VEGF medications.

All eyes were injected with intravitreal Bevacizumab $1.25 \mathrm{mg}(0.05 \mathrm{~mL})$ of commercially available Bevacizumab. At baseline and follow up visits patients were measured for Best Corrected Visual Acuity (BCVA), Intraocular pressure (IOP) assessment, dilated fundus examination, slit lamp biomicroscopy with Volk 90 diopters lens, fundus photography, contrast sensitivity; stereopsis, Fluorescence and Angiography (FA) and Optical Coherence Tomography (OCT) imaging were used for measurement of Central Retinal Thickness (CRT). OCT was performed for all of patients. Readings for $1 \mathrm{~mm}$ CRT were obtained from the mean retinal thickness in the central subfield using six linear scans $6 \mathrm{~mm}$ long centred on fixation and processed as a retinal map.

Stereoacuity was assessed by the Frisby stereo test using standard procedure with suitable reading addition for the particular testing distance. An upright plate holder, head, and chin rest prevented monocular clues. Frisby plates were held squarely in front of the participant to avoid reflections and parallax and displayed from circle being seen to circle not seen in crossed disparity. Two-down, one-up staircase procedure was used in 10-cm steps to determine the threshold. The participants identified one picture correctly out of four pictures, three out of four times correctly in 4AFC (Four Alternate Forced Choice) method.

In all patients, the intravitreal injection of off label bevacizumab were performed in a standard protocol in the operating theatre under operating ophthalmoscope and complete aseptic condition after obtaining informed consent. Scrubbing of the eye lids and lashes with $10 \%$ of Povidone iodine was done. A sterile eyelid speculum was used for all injections; sterile cotton swab shocked with 
Lidocaine $2 \%$ were applied at the site of bevacizumab injection in the inferotemporal quadrant. Bevacizumab were injected through the pars plana $3.5-4.0 \mathrm{~mm}$ posterior to the surgical limbus using a 30 -gauge needle at a dose of 1.25 $\mathrm{mg}$ in $0.05 \mathrm{~mL}$. Post injection, a sterile cotton swab was placed at the site of injection to prevent reflux of vitreous or drug, light perception was assessed and indirect ophthalmoscope done to see optic nerve head perfusion.

After the injection, the patients did not apply any topical antibiotics. Postoperative follow up included repeat clinical examinations and OCT in all the patients. Patients were assessed for adverse events including elevated intraocular pressure, cataract progression, retinal detachment, postinjection inflammation, and endophthalmitis. Follow up evaluations were scheduled to next day, 1 week then monthly till the end of follow up. Repeated OCT was done at 1 month and at the end of follow up, about 12 months. A repeated injection of Bevacizumab was performed for persistent or recurrent CSC seen and documented by OCT imaging.

The main outcome included changes in stereopsis, contrast sensitivity, BCVA and CRT using OCT. Secondary outcome included any systemic or ocular adverse effects of injection and the need for repeated injections.

Statistical analysis was assessed using (SPSS-21 version). All variables were expressed as mean \pm standard deviation (SD), the Wilcoxon sign rank test was used and $\mathrm{p}$ value $<0.05$ was considered statistically significant.

\section{RESULTS}

In this prospective study, 15 eyes of 15 patients received intravitreal Bevacizumab injection. The mean age of all patients was 35 years (range 26-47 years), $12(80 \%)$ patients were males and three
Table 1. Duration of visual disturbance on presentation

\begin{tabular}{|l|l|r|}
\hline Duration & Eyes & Percentage (\%) \\
\hline$\geq 3$ to 6 months & 13 eyes & $86.70 \%$ \\
\hline$\geq 6$ months & 1 eye & $6.65 \%$ \\
\hline $\begin{array}{l}\text { Recurrent } \\
\text { CSCR }\end{array}$ & 1 eye & $6.65 \%$ \\
\hline Total & 15 eyes & $100 \%$ \\
\hline
\end{tabular}

$(20 \%)$ were female. All patients presented with history of diminution of vision, and scotoma with visual acuity of most of the patients in the range of $6 / 12$ to $6 / 60$. The mean follow up period was 12 months. 13 out of 15 subjects received only one injection while the remaining two cases had two injections.

On fundus fluorescein angiography of 15 patients, hyper-fluorescence with ink-blot appearance was seen in 13 eyes (86.7\%) smoke-stack appearance in eight eyes $(53.33 \%)$ and diffuse in three eyes $(20 \%)$. The number of leak in FFA was one to three leaks and two patients had asymptomatic leaks in fellow eye.

There were neither systemic nor intraocular adverse effects seen in our study except some sort of subconjunctival haemorrhage at the site of injection resolved spontaneously with time in three patients. All of eyes had visual improvement; all eyes had gained two or more lines improvement in BCVA at the end of follow up. None of eyes had decreased vision than the baseline BCVA.

There was decrease in the mean of CRT all over the time which was correlated with the improvement in both of BCVA and FA leakage. The mean baseline CRT for all patients was $533 \pm 79.5 \mathrm{~lm}$ (range, 412 677), decreased to $253 \pm 39.2 \mathrm{~lm}$ (range, 192-343) after 12 months with statistically significance (p $<0.001$ Wilcoxon sign rank test). Contrast 
sensitivity by Wilcoxon sign rank test was statistically significant with $\mathrm{p}$ value 0.003

\section{DISCUSSION}

CSCR is a benign self-limited condition characterised by idiopathic serous detachment of the neurosensory retina. A number of hypotheses have been proposed regarding the pathophysiology of CSCR. Dysfunction of the RPE with reversal of liquid transport may play a role in the development of serous retinal detachment. ${ }^{13,14}$

In some cases, earlier intervention may be necessary due to high occupational demands for binocular vision. There are some studies in the literature supporting the benefit of early treatment of CSCR. These studies propose that the potential advantage of early resolution may be mediated by a lower rate of RPE degeneration in treated eyes. ${ }^{15,16}$ In some studies, the possible benefits of an antiVEGF agent in CSCR were proposed on the basis of choroidal ischemia and hyperpermeability as pathogenethic mechanisms of CSCR.17,18,19 Attempts to treat acute and chronic CSCR with intravitreal Bevacizumab are based on the hypothesis that choroidal hyperpermeability is associated with increased expression of VEGF. ${ }^{20}$ Intravitreal Bevacizumab can terminate RPE leaking and prompt resolution of subretinal fluid, which can be associated with rapidly improving vision and remain stable. Although the exact mechanism of Bevacizumab in chronic CSC is unknown, it may be due to the effect of antimicrovascular permeability.

In our study all eyes had gained two or more lines improvement in BCVA at the end of follow up. None of eyes had decreased vision than the baseline BCVA which was similar to the study done by Mitzy E et al.21
The mean baseline CRT for all patients was 533 $\pm 79.51 \mathrm{~m}$ (range, $412-677$ ), decreased to $253 \pm 39.2$ $1 \mathrm{~m}$ (range, 192-343) after 12 months with statistically significance $(\mathrm{p}<0.001$ Wilcoxon sign rank test). These results are in agreement with the outcome of the study of Mehany et al. ${ }^{22}$ Their results showed that intravitreal Bevacizumab injection was associated with visual improvement and reduced neurosensory detachment. In their study mean number of injections used were two. These results are also in agreement with the results of Torres-Soriano et al. who reported in a study of six eyes that visual acuity improved in all cases by one month after treatment (intravitreal Bevacizumab injection) and remained stable until the examination at the third month. ${ }^{23}$

There were neither systemic nor intraocular adverse effects seen in our study except some sort of subconjunctival haemorrhage at the site of injection , which resolved spontaneously with time in three patients.

There were no cases of recurrence at the end of follow up. Small number of patients and lack of control group is the limitation of our study.

\section{CONCLUSIONS}

Intravitreal injection of Bevacizumab was associated with visual function improvement and reduced neurosensory detachment without adverse events in patients with CSCR. Anti-vascular endothelial growth factor treatment offers a new medical treatment modality with promising results. However a large number of patients with longer follow up period are necessary to confirm the efficacy and safety of bevacizumab and determine the ideal protocol for this new promising treatment. 
To cite this article: Shrestha C, Shrestha S, Manoranjan A. Evaluation of Visual Function Test of Central Serous Chorioretinopathy after Intravitreal Bevacizumab. MJSBH. 2019;18(1):37-42.

Conflict of Interest: None declared

\section{REFERENCES}

1. Gass JD. Pathogenesis of disciform detachment of the neuroepithelium, II idiopathic central serous choroidopathy. Am J ophthalmol. 1967;63:587-615.

DOI: https://doi.org/10.1016/0002-9394(67)90027-X

2. Spaide RF, Hall L, Hass A, Campaes L, Yamuzzi LA. Indocyanine green video angiography of older patients with central serous chorioretinopathy. Retina. 1996;16:203-13

DOI: https://doi.org/10.1097/00006982-199616030-00004_ PMid:8789858

3. Gilbert CM, Owens SL, Smith PD, Fine SL. Long-term follow-up of central serous chorioretinopathy. Br. J. Ophthalmol. 1984;68:815-20.

DOI: https://doi.org/10.1136/bjo.68.11.815 PMid:6541945 PMCid:PMC1040477

4. Hussain D, Gass JD. Idiopathic central serous chroioretinopathy. Indian J Ophthalmol. 1998;46:131-7. PMid:10085624

5. Berger AR, Olk RJ, Burgress D. Central serous chroioretinopathy inpatients over 50 years of age. Ophthalmic Surg. 1991;22:583-90.

PMid:1961615

6. Gass, JDM. Stereoscopic Atlas of Macular Diseases: Diagnosis and Treatment. Vol. 2. 3rd ed. CV Mosby, St. Louis; 1986:46-59.

7. Yang JC, Haworth L, Sherry RM et al. A randomized trial of bevaciumab, an anti-vascular endothelial growth factor antibody for metastatic renal cancer. N Engl J Med. 2003;349:427-34.

DOI: https://doi.org/10.1056/NEJMoa021491ＰMid:12890841 PMCid:PMC2275324

8. Karim SP, Adelamn RA. Profile of veteporifin and its potential for the treatment of central serous chrorioretinopathy. Clin Ophthalmol. 2013;7:1867-75.

PMid:24092965 PMCid:PMC3788817

9. Aydin E. The efficacy of intravitreal bevacizumab for central serous chrorioretinopathy. J Ocul Pharmacol Ther. 2013;29(1):10-3.

DOI: https://doi.org/10.1089/jop.2012.0072PMid:22925113

10. Jamil AZ, Rhadman FU, Iqbal K, Ausari MH, Iqbal W, Miraz KA. Intravitreal bevacizumab in central central serous chrorioretinopathy. J Coll Physicians Surg Pak. 2012;22(6):363-6.

PMid:22630094

11. Caccavale A, Romanazzi F, Imparato M, Negri A, Morano A, Ferentini F. Central serous chrorioretinopathy - a pathogentic model. Clin Ophthalmol. 2011;5:239-43.

DOI: https://doi.org/10.2147/OPTH.S17182～PMid:21386917 PMCid:PMC3046994

12. Niegel MF, Schrage NF, Christmann S, Degenering RF. Intravitreal bevacizumab for chromic CSCR. Ophthalmologe. 2008;105(10):943-45.

DOI: https://doi.org/10.1007/s00347-008-1691-5 PMid:18214491

13. Piccolino FC, de la Longrais RR, Ravera G, Eandi CM, Ventre L, Abdollahi A, et al. The foveal photoreceptor layer and visual acuity loss in central serous chorioretinopathy. Am J Ophthalmol. 2005;139:87-99.

DOI: https://doi.org/10.1016/j.ajo.2004.08.037ＰMid:15652832 
14. Lim JW, Kim MU, Shin MC. Aqueous humor and plasma levels of vascular endothelial growth factor and interleukin-8 in patients with central serous chorioretinopathy. Retina. 2010;30:1465-71 DOI: https://doi.org/10.1097/IAE.0b013e3181d8e7fe＿PMid:20526231

15. Wang MS, Sander B, Larsen M. Retinal atrophy in idiopathic central serous chorioretinopathy. Am J Ophthalmol. 2002;133:787-93. DOI: https://doi.org/10.1016/S0002-9394(02)01438-1

16. Fuhrmeister H. A long term study of morphological and functional developments after central serous chorioretinitis. Klin Monbl Augenheilkd. 1983;182:549-51.

DOI: https://doi.org/10.1055/s-2008-1054851PMid:6876650

17. Inoue M, Kadonosono K, Watanabe Y, Kobayashi S, Yamane S, Arakawa A. Results of one year follow up examinations after intravitreal bevacizumab administration for chronic central serous chorioretinopathy. Ophthalmologica. 2011;225:37-40.

DOI: https://doi.org/10.1159/000314709ＰMid:20693820

18. Artunay O, Yuzbasioglu E, Rasier R, Sengul A, Bahcecioglu H. Intravitreal bevacizumab in treatment of idiopathic persistent central serous chorioretinopathy: A prospective, controlled clinical study. Curr Eye Res. 2010;35:91-8.

DOI: https://doi.org/10.3109/02713680903428306 PMid:20136418

19. Lim SJ, Roh MI, Kwon OW. Intravitreal bevacizumab injection for central serous chorioretinopathy. Retina. 2010;30:100-6.

DOI: https://doi.org/10.1097/IAE.0b013e3181bcf0b4ＰMid:20010322

20. Seong HK, Bae JH, Kim ES, Han JR, Nam WH, Kim HK. Intravitreal bevacizumab to treat acute central serous chorioretinopathy: short term effect. Ophthalmologica. 2009;223(5):343-7.

DOI: https://doi.org/10.1159/000224782ＰMid:19521133

21. Soriano ME, Aguirre GG, Angelozzi MG, Jara VK, Guerra JF, Ober MD, et al. Intravitreal Bevacizumab for the treatment of chronic or recurrent central serous chorioretinopathy. OJOph. 2014 Jul;4(03):57..

DOI: https://doi.org/10.4236/ojoph.2014.43010

22. Mehany SA, Shawkat AM, Sayed MF, Mourad KM. Role of Avastin in management of central serous chorioretinopathy. Saudi J Ophthalmol. 2010;24:69-75.

DOI: https://doi.org/10.1016/j.sjopt.2010.03.002ＰMid:23960879 PMCid:PMC3729398

23. Torres-Soriano ME, García-Aguirre G, Kon-Jara V, Ustariz-Gonzáles O, Abraham-Marín M, Ober MD, et al. A pilot study of intravitreal bevacizumab for the treatment of central serous chorioretinopathy (case reports) Graefes Arch Clin Exp Ophthalmol. 2008;246:1235-9.

DOI: https://doi.org/10.1007/s00417-008-0856-x PMid:18523796 